\title{
TRANSLATOR'S ACTIVITY AND KNOWLEDGE BASE IN LITERARY TRANSLATION
}

\author{
Khalilova Olima \\ Senior teacher of the Foreign Languages Department, Karshi Engineering-Economics Institute, \\ Karshi City, Uzbekistan
}

\author{
Abdirakhimova Mokhigul \\ Senior Teacher of the Foreign Languages Department, Karshi Engineering-Economics Institute, \\ Karshi City, Uzbekistan
}

Article DOI: https://doi.org/10.36713/epra5687

\begin{abstract}
Translation skills are the most important part of translation and can complement the other two. If the translator does not have enough knowledge and experience, it will be difficult for the translation to be complete. If these two qualities are sufficient, he can use creative methods to translate even a low-level work in a level view and fully meet the needs of the customer.
\end{abstract}

KEYWORDS: translation, process, knowledge base, grammar translation linguistic activity, inter linguistics, inter lingual, speaker, content.

\section{DISCUSSION}

The analysis of the cognitive features of the translation process requires the identification of the conceptual foundations of the translation activity, without which the ability to interpret the facts of the field collected over a long period of time is lost. One of such conceptual bases is, of course, that the activity of translation depends on the knowledge base, because every rational action is carried out within the existing knowledge. The accumulation of knowledge is a gradual process, it is difficult to acquire it urgently or involuntarily, it is mainly accumulated on the basis of knowledge, step by step. Even knowledge acquired through indirect means of information must pass certain tests to become a reality. . The work of an interpreter is one of the types of intellectual, step-by-step, intelligent activity.

On the first page of his 1965 book, J. Kathford, an English translator, suggested that translation be seen as an "Operation Performed on Languages" because in the process "a text in one language is confused with another." It is clear, he concludes, that the theory of translation must be based on a particular linguistic theory or a general linguistic theory. It is worth joining the second part of Ketford's commentary, as it draws on translation studies, more precisely on language theory. It uses some analytical ideas based on its advanced methods.

But the inter linguistic alternatives of the texts do not seem to suggest that "the grammar and vocabulary of the original language are exchanged with the grammar and dictionary of the target language, and consequently the phonology of the two languages, the place of writing." Although we believe that the translation process consists of transformations, stages of inter lingual migration, it is difficult to say what happens to such a migration and how the migration takes place. It has become customary to interpret translation as the expression of the meaning of a text in one language in another. We all believe in this belief. At the same time, we have always witnessed how difficult it is to preserve meaning [1, p. 4].

The well-known Edward Sepir hoped to emphasize that in the 1930 s there was no possibility of translating literary texts, and that the possibility of 


\section{EPRA International Journal of Research and Development (IJRD)}

scientific translation was explained by the existence of "some common language without outer garments" in the statement of scientific facts. According to him, "a word is a form that is sometimes more or less mastered from the conceptual material of thought, depending on the spirit of a particular language." Describing the word only as a phenomenon with a form, E. Sepir considers the part of its emotional meaning to be devoid of linguistic value. Even the emotional meanings of the English words stormthunder, tempest- storm, hurricane- hurricane can not dissuade the scientist from his own opinion, and in his opinion, "the emotional tone of the word is useless for science." It is also surprising that in the end, artists are advised to "find ways to get rid of the emotional tones that cling to words and return them to a purely conceptual meaning".

Who doesn't know that art is directly related to psyche, emotional expression !? As the French literary critic J. Sartre put it, "the language of art knows no boundaries, it evokes the senses of taste and smell"' [2, p. 6].

In fact, the creators choose the words according to their feelings and thoughts, at a level that evokes the necessary imagination in the students. As Alisher Navoi wrote in Muhokamatul-lug'atayn, and the first two of them mean "secretly weeping with pain," and the last one is an exaggeration of weeping.

Is it possible to ignore the subtleties of meaning? When the meaning consists only of a reference piece, it is inconceivable that the word could, in the words of Alisher Navoi, "enchant and decorate the imagination." The emotional-spiritual part of the meaning plays an important role in the formation of the aesthetic content of the text. Moreover, this part is expressed in each language in its own way, because the different worldviews and attitudes of people of different cultures and nationalities can rarely match. Even when writing a text about a single event, attention is paid to the indicators of specific situations in different languages. These indicators have a cultural significance, but sometimes they also depend on the characteristics of the language system. A simple example: the English and Uzbek "I've arrived" and "I came" structures are almost equally valuable and can be easily considered as equivalents. However, translating these structures into Russian poses some difficulties.

In translation studies, there are a number of theories aimed at determining the adequacy of translation, sorting translations, and providing a scientific and theoretical assessment of the translator's skills. Theory, on the other hand, is naturally updated and enriched by modern theories over time. One of the theories in this new direction is the theory of cognitive dissonance. The essence of this theory is to identify adequate translations, to study the causes of the factors that hinder the achievement of adequate translation, and to find ways to reduce and eliminate them as much as possible in the translation process. Before defining the problem of cognitive dissonance that underlies this theory and its place in literary translation, it is necessary to study the essence of this phenomenon.

Cognitive linguists prefer to approach the interpretation of the phenomenon of meaning in terms of the activation of linguistic units of semiotics in the context. At the heart of this interpretation is the idea that meaning is a content that can be understood in an environment of direct activation, rather than a "innate" heritage of language unity. Of course, the role of linguistic elements in speech structure is significant. This share alone is not enough to understand. The conceptualization of reality comes to the fore here. In the same context, the speaker forms the semantic content of the thought, emphasizes the important aspects of the participants of the speech structure, adapts it to the accepted worldview. In this sense, it seems more plausible to interpret meaning in the interpretation of a text or other linguistic unit as an event that is created as a result of cognitive actions performed by the user of the language, rather than a ready-made whole. In that case, it is more appropriate to suggest that the activity of translation also arises from the practice of re-creation in a new environment or context, rather than from the practice of transferring meaning from one language to another.

\section{LIST OF USED LITERATURE}

1. Ziyadullayeva. $U$. The problem of cognitive dissonance in literary translation. Samarkand.2020. P-34-41.

2. Catford J.C. A Linguistic Theory of Translation; An Essay in Applied Linguistics. Oxford: OUP, 1965.P-4;

3. Sartre J.P. What is literature? - Harvard: Harvard Univ. Press, 1988. P-6;

4. Rivers, Wilga. Teaching Foreign Language Skills. Chicago: University of Chicago Press. 1968, 62-72 p.

5. Richards, J. C., and Rogers, T. S. Approaches and methods in language teaching: A description and analysis. Cambridge: CambridgeUniversity Press. 2001, 87-97 p.

6. Brown, H. Douglas. Teaching by Principles: An Interactive Approach to Language Pedagogy, Second edition. New York: Addison Wesley Longman, Inc. 2001, P-97.

7. Halliday, M. A. K. Spoken and written language. Oxford: Oxford University Press. 1989, -31 p.

8. M. Erkinova. Audition as a method of boosting of a level in the English language. Samarkand. 2020. P-8-16. 